was brought about under these relatively difficult conditions, and living mites were not found in the old lesions, it is thought that in all probability hexachlorobenzene will ultimately prove to be of great value in the treatment of psoroptic scabies (including 'sheep scab') in animals, and of sarcoptic scabies in animals, and also in man.

Veterinary Laboratory,

(Ministry of Agriculture), Weybridge. Feb. 7.

\section{'D.D.T.' as a Sheep Blowfly Dip}

THE powerful toxic action of 'D.D.T.' on many species of flies has made possible a new method of attack against the sheep blowfly Lucilia sericata $(\mathrm{Mg})$ and related species. As the following experiments indicate, control may be achieved by the direct action of a 'D.D.T.' dip on the blowfly while the insect is searching the fleece for a site suitable for egg-laying.

The preliminary laboratory experiments were made by Dr. E. T. Burtt of the Unit of Insect Physiology (Agricultural Research Council), who showed that sheep wool dipped in an emulsion containing 0.5 per cent 'D.D.T.' was toxic to laboratory-bred specimens of $L$. sericata. The following field tests gave results in keeping with this observation and demonstrated that the toxic effect could take place rapidly enough to prevent gravid females of $L$. sericata from ovipositing on sheep.

Two dipping trials were made on farm flocks consisting mainly of Welsh mountain sheep. In both cases the same dipping procedure was adopted and the same 'D.D.T.' emulsion ( $M 21)$ used.

In the first trial eighty-one sheep were dipped, the concentration of the bath falling from 0.3786 to $0 \cdot 3264$ per cent 'D.D.T.' in the course of the dipping. The sheep remained free from strike throughout the period of the experiment, August 8-September 18, a total of forty-two days. It was not possible to have a control group grazing with the experimental flock; but chemotropic experiments made on this particular farm indicated that conditions for strike were better in August and September than in the four weeks prior to dipping, when ten strikes were recorded in the flock. Further, bad cases of maggoting were reported on neighbouring flocks.

The second trial comprised a total of 430 sheep grazing on five different regions of one farm. Each grazing unit was divided into two equal groups as regards breed, age and sex. One group was dipped with the 'D.D.T.' emulsion and the other with a commercial arsenical dip. The 'D.D.T.' concentration fell from 0.4540 per cent to 0.2388 per cent in the course of the dipping.

The experiment lasted from August 29 to October 13, a period of forty-four days. Three strikes occurred on 'D.D.T.'-dipped sheep; one of these was a restrike. Twenty-one strikes occurred in the control group which had been dipped with the commercial preparation; no re-strikes were recorded in this group. In the control group the first strike occurred six days after dipping and in the 'D.D.T.' group twenty-four days after dipping, by which time thirteen strikes had been recorded on the controls.

The following experiments clearly show that the effectiveness of the dip lay in its direct action on the blowfly.
Three weeks after dipping, specimens of $L$. sericata were captured from undipped and 'D.D.T.'-dipped sheep. Of twenty-five flies caught on the undipped sheep, two died in twenty-four hours. Of thirteen caught on the 'D.D.T.' group, nine died in twentyfour hours. All the flies which died, including those caught on the control group, showed symptoms of 'D.D.T.' poisoning within $15-30$ minutes of capture. A similar test five weeks after dipping showed one death out of sixteen flies captured on the controls and five out of sixteen captured on the 'D.D.T.' group.

Tests in which gravid females of $L$. sericata were kept in contact with the fleece of a 'D.D.T.'-dipped sheep showed that even five weeks after dipping, 30-60 seconds contact was sufficient to have a toxic effect on the flies.

The action of the dip in preventing oviposition was clearly demonstrated by tests with artificial attractants. The Hobson ${ }^{1}$ technique was employed, and five 'D.D.T.'-dipped with five undipped sheep were used in each experiment.

NUMBER OF EGg BATCHES LAID IN REGION OF ATTRAOTANT.

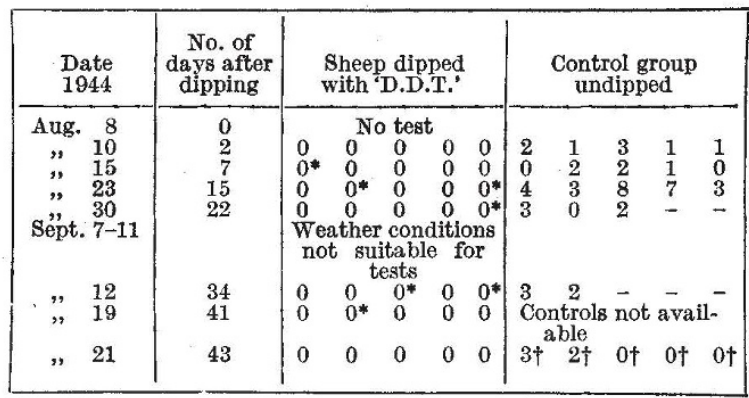

* From 3-6 scattered eggs laid, except in the case on September 19 when 15 eggs were found.

The sheep used as controls on September 21 had been dipped with a proprietary arsenic dip on September 19.

The accompanying table summarizes the results obtained. On no occasion was a complete and compact batch of eggs laid on the 'D.D.T.'-dipped sheep, whereas oviposition was invariably induced on the control group. The results obtained on September 21 are of particular interest because the control group had been dipped with a proprietary arsenic dip only two days previously and their fleeces were sticky and had a strong odour; yet oviposition occurred on them but not on the sheep which had been dipped with 'D.D.T.' some six weeks previously.

In the course of the 1945 blowfly season, the dip is to be given extensive field trials and attempts are to be made to increase its effectiveness by combining an attractant with it, thus making the dipped sheop act as blowfly traps.

I wish to thank Mr. L. Davies for assistance with the field experiments and Dr. J. G. Mitchell of the D.S.I.R. Chemical Laboratory for the preparation of the 'D.D.T.' emulsion and for determining the 'D.D.T.' concentrations mentioned above.

\section{Agricultural Research Council, \\ Unit of Insect Physiology, \\ at the School of Agriculture, \\ University College of North Wales, Bangor.}

${ }^{1}$ Hobson, R. P., Ann. Appl. Biol.., 24, 627 (1937). 